\title{
Employment Status of Teaching Positions of Scheduled Castes (SCs) and Scheduled Tribes (STs) in Selected Central Universities in India
}

\author{
Dr. J. B. Komaraiah* \& Ms. Shree Priya Singh**
}

\begin{abstract}
The government has instituted a policy of "reservations" whereby a certain percentage is reserved for the castes that are considered to be low in the caste hierarchy and for the aborigines or tribes who were traditionally excluded from education. The number of Universities had gone up to 574 universities-(44 Central, 286 State, 111 State Private, 129 Deemed to be Universities, four Institutions established under State Legislation) as on 31.03.2012. UGC has provided the data of faculty strength (on 01/01/2014) of total 39 central Universities in different 29 States with total of 15, 573 sanctioned teaching staff in India. In this paper, an attempt has been made to focus on the main objectives of sanctioned posts; filled-up posts; short-fall positions and the employment status of SC/ST employees of Professor, Associate Professor and Assistant Professor levels in the selected central universities i.e. Banaras Hindu University (BHU), Delhi University (DU), Jawaharlal Nehru University (JNU) and University of Hyderabad $(\mathrm{UoH})$ in India.
\end{abstract}

\section{Introduction}

Higher education in India is made up of regular education and distance education. There are four types of regular education (general, technical, medical and agricultural) with each type divided into university level and college level education. In addition, institutes of higher learning and research in science, technology, management, medicine, social sciences and humanities have the status of deemed universities or autonomous institutions and provide higher education. Distance education is university-based and is limited to undergraduate and post-graduate degree and diploma courses in general and technical education (Narayana, 2002). Under the Constitution (42nd Amendment) Act of 1976, both the Federal/Central/Union and the State Governments are responsible for the promotion and development of higher education. The University Grants Commission (UGC) was established in 1956 by an Act of Parliament, is responsible for funding, coordinating, monitoring and maintaining the universities in the country. Central or State governments set up universities by means of legislation.

Despite its expansion, enrollment in higher education in India, today accounts for barely 6 percent of the relevant age group (because of growth in population in the relevant age group) and facilities fall short of demand in some professional programs and there are more than 500 applicants per seat (Chitnis, 1999, 26). In an effort to equalize the access, the government has instituted a policy of "reservations" whereby a certain percentage of admissions are reserved for the castes that are considered to be low in the caste hierarchy and for the aborigines or tribes who were traditionally excluded from education. (Chitnis, 1999).

For admission into university level studies, the students must have senior/higher secondary school certificates with some institutions setting minimum marks on the Higher Secondary Examination and others requiring the students to sit for admissions tests. Certain centrally sponsored institutes and universities and the Indian Institutes of Technologies require students to take the Joint Entrance Examination.

To finance higher education expansion, the government has consistently increased its share in the total expenditure on higher education, from 49.1 percent in 1950-51 to more than 90 percent in 1999 (Chitnis: 1999). Students pay a nominal fee that constitutes 10 to 15 percent of the budget of the institution (Maiti, 2001; Tilak, 1997). However, some data suggests that fee contributions may vary considerably between Central and state institutions with student fees contributing a significant amount to university income in the state universities. For example, in 1990, in the University of Madras, nearly half of the total income was from student fees (Tilak: 1997). Several universities offer fee waivers to women students. The higher education financing system is beginning to change and a policy of fostering financial independence in universities and degree colleges (reducing government allocations to universities and increasing user fees) has been in place since 1997. Despite the policy pronouncements over the last six years, however, it is only fairly recently that action has been taken. While the UGC has the legal right to set tuition and fees, it has not done so - in practice, it is the individual state governments and institutions that take the initiative. 
Employment Status of Teaching Positions of Scheduled Castes (SCs) and Scheduled Tribes (STs) ....

\section{Growth Scenario of Higher Education in India}

The Indian higher education sector has expanded at a phenomenal rate in the last century. The European system of higher education was introduced in India by the British in 1857 with the establishment of universities for European education in three cities and withdrawal of support for indigenous education. By India's independence in 1947, an additional 18 universities had been established. In 1950-51 when the country's First Five Year Plan was launched, there were 27 universities serving 1,74,000 students (Chitnis, 1999). By 1997 there were 229 universities (composed of general universities; science and technical universities; open universities; agricultural universities; women's universities; language universities; and medical universities), more than 8,000 colleges, and 6.4 million students, making India's system of higher education the second largest in the world.

The number of Universities had gone upto 574 universities-(44 Central, 286 State, 111 State Private, 129 Deemed to be Universities, four Institutions established under State Legislation) as on 31.03.2012. During the year under report 2011-2012, 21 State and 31 State Private Universities were included in the UGC list of universities and 12 state universities were declared fit to receive central assistance under 12 B of the UGC Act. The strength of the teaching faculty in universities and colleges had gone up to 9.34 lakh as compared to 8.17 lakh teachers in the previous year, registering an increase of $14.32 \%$. Out of 9.34 lakh teachers, $83.09 \%$ teachers are in colleges and the remaining $16.91 \%$ in universities (UGC Annual Report of 2011-2012).

During 2011-12, the number of Central Universities by excluding the South Asian University \& Nalanda Universities stood at 42. Out of these, three universities namely, Indira Gandhi National Open University, Central Agricultural University and Indian Maritime University are directly funded by the Ministry of Human Resource Development, Ministry of Agriculture and Ministry of Shipping \& Transport respectively. The funding for South Asian and Nalanda Universities is being made by the Ministry of External Affairs. Hence, during 2011-12, only 39 Central Universities were assisted by the UGC by providing Plan and Non-plan grants. UGC has provided the data on faculty strength (on 01/01/2014) of total 39 central Universities in different 29 States with the total of 15,573 sanctioned teaching staff in India. There are total 17 Central Universities in Non-NER states with total 11,202 sanctioned teaching staff; 9 Central Universities in North Eastern Region (NER) states with total 2, 453 sanctioned teaching staff; and 13 new Central Universities established in different 12 states of India with the total 1 , 918 sanctioned teaching staff. In Non-NER Central Universities, out of 17 Central Universities in different 9 States of India; the maximum 4 Central Universities are located in Utter Pradesh with 4, 363 total sanctioned teaching staff, followed by 3 central Universities in Andhra Pradesh and Delhi; 2 central Universities in Madhya Pradesh, and one central University each in Chhattisgarh, Maharashtra, Puducherry, and in Uttarakhand. In NER region, two Central Universities are located in Assam and one Central University each in different 7 states; namely, Arunanchal Pradesh, Manipur, Meghalaya, Mizoram, Nagaland, Sikkim, and in Tripura. Out of total 13 new central Universities two Universities are located in Jammu \& Kashmir; and one Central University each located in different 11 states namely Bihar, Gujarat, Haryana, Himanchal Pradesh, Jharkhand, Karnataka, Kerala, Orissa, Punjab, Rajasthan, and in Tamilnadu.

\section{Review of Literature}

The reservations have to be limited to admissions into institutions of education because the people can handle the decision making with the right capability; but when an incapable person who gets admission into a university is inefficient and hardly qualifies this person to get the job. Then the person's inefficiency shows nevertheless this person gets a promotion (Apana: 1990). The reservation policy for backward classes is a major barrier in achieving the efficiency because of merit or efficiency. This is an essential ingredient in every field of life such as space, atomic energy, aeronautics, electronics, scientific and industrial research and hospitals. If India is to survive as a nation in this world, it has to strive for the highest standards of efficiency in every field and remove all barriers related efficiency. Reservations for backward classes in jobs in government establishments and public sector undertakings are one of the major barriers. The author suggested that the policy of job reservations needs to be replaced by effective programmes of affirmative action to promote efficiency, merit and skills among the weaker sections of the society. Primary education and other programmes linked with it should receive the highest priority. Maximum attention should be given to the lowest level so that affirmative action at the higher levels can also become effective. This does not mean that we abandon the goal of social justice, but use different methods to achieve the same goal (Shah: 1991).

The government has rejected the economic basis as the criterion to give reservation. The recent controversy regarding caste being a part of race or other-wise, also originated in the nature of social backwardness itself. Backwardness in short is a community phenomenon. It is therefore logical to think of a remedy which takes an entire caste and not an individual into consideration, and does not necessarily insist purely on an economic criterion. 
Employment Status of Teaching Positions of Scheduled Castes (SCs) and Scheduled Tribes (STs) ....

Let it be remembered- poverty emanates from social backwardness, but the reverse is not necessarily true. The issue of reservations for the dalits and the backward castes is therefore not to be confused with any poverty alleviation programme or an employment generation scheme. The backwardness of a caste is moving many castes or caste groups were actually to be identified as the really backward ones. But something has been changed on account of several developments in the last four or five decades of the post-colonial politics in India. Some castes have become politically powerful and socially dominant. One may characterize the politics of the last few decades as yadavisation and kurmiaisation of politics in Bihar and UP. A similar pattern may be observed else-where like in Karnataka where the vokkaligas and the lingayats (non-backward as per the Havanur Commission) have successfully resisted their exclusion from the list of the backwards (the Mandal Commission included both in the backward category), and have consequently succeeded in capturing political and economic power. The democratization of politics thus resulted in the political empowerment of the more numerous and relatively wealthy backward castes in the decades following independence (Pradeep Kumar: 2001).

The Delhi University adopted the policy of reservation for SC/ST in recruitment only to group C and D posts in October 1974. Due to pressure from the UGC and the government the university eventually accepted the policy of reservation in recruitment to teaching posts at the lecturer level after 1996. Since then appointments under the reserved category are being made in the university and its affiliated colleges. In 1997 the position of the university Departments shows that the, 3 professors (SC 3: ST 0) out of 351; 2 readers (SC 1; ST 1) out of 210 and 7 lecturers (SC 6; ST 1) out of 127. With some improvement in recruitment of SC/ST in teaching posts is visible. The data for 2000-01 for the university departments is a pointer. In that year, there were in all 3 professors (SC 2 and ST 1 out of 295), 3 readers (SC 2; ST 1 out of 191) and 13 lecturers (SC 11; ST 2 out 130) holding teaching positions in the university (Xaxa :2002).

The Indians have divided into two divisive camps like pro and anti reservationists. The latter argues that merit has often taken second place as a result of such policies that anyway benefit only a certain sections, already privileged, among the disadvantaged. But data collected by the author from various sources reveal that the SCs and STs continue to be poorly represented in government services and they score far lower than the most of other sections in several development indicators, chiefly literacy. Affirmative action and human rights are often seen as conflicting political measures. But, the affirmative action is aimed at extenuating societal disadvantages derived from socio-historical processes of an unjust social order. Efforts to uphold human rights on the other hand are aimed at ensuring the rights of every citizen. An Affirmative action is usually defined as that measure which is aimed at minimizing, if not doing away, with discrimination and deprivation. The examination of the socio-economic profile of the scheduled castes and scheduled tribes shows that there has been no marked improvement in their social condition like literacy, employment in public sector, even after five decades of implementation of reservation policies. In every sector, discrimination was practiced without any penalty. Actual representation shows that this legal provision of reservation has been grossly violated at both state and central levels (Louis: 2003).

By implementation of reservation policy the constraints can be removed which are imposed by the caste discrimination on labour markets, and thereby induce competitiveness and economic growth. It will provide fair and non-discriminatory access to historically excluded and discriminated groups like the dalits. In a caste-divided society, the choice of occupation is not based on individual preferences or capabilities, but is decided by birth in a particular caste. Caste becomes a direct cause of much of 'voluntary unemployment' among high caste persons and 'involuntary unemployment' among the low castes. Economic theories of caste imply that restrictions on labour mobility create huge imperfections and inefficiencies in the competitive allocation of labour, and produce less than optimum economic outcomes, besides denying fair access to the discriminated groups (Thorat: 2005).

During the last fifty years or so, the share of SC/STs in the government services has improved quite significantly. There are, however, variations between different types of jobs. Generally, reservation is fairly proportionate to the required percentage in group $\mathrm{C}$ and $\mathrm{D}$ jobs; but unsatisfactory in the case of $\mathrm{A}$ and $\mathrm{B}$ category jobs. For instance, in 2003, the lower categories of jobs, i.e. C and D grade posts accounted for almost 95 percent of the total SC/ST posts under reservation in government. The target in case of grade $\mathrm{C}$ and D jobs are fairly close to the reservation percentage earmarked: 16 per cent for SCs and 8 per cent for STs; but in grade A and B jobs, and also in several categories of technical and university jobs, the fulfillment of quotas fell short. Over time, there has been a positive improvement in the human development of SC/STs. The positive changes are reflected in the aggregate indicators of human development - income level, employment, social needs like education \& health, and ultimately, in poverty. But the disparities between SC/STs and non SC/ST have not been reduced substantially so as to bridge the gap to a reasonable level. Despite legal measures in seeking legal safeguards against discrimination in employment, education and other spheres, the SC/STs continue to suffer from discriminatory access to the institutions of justice which are responsible for delivering justice. The concept of 'creamy layer' like OBC has not 
Employment Status of Teaching Positions of Scheduled Castes (SCs) and Scheduled Tribes (STs) ....

been applied to SC/STs, because the ones who are relatively better off, as well as the ones who are worse off, continue to suffer from discrimination and non-participation in development processes (Thorat et al. :2005).

The reservations were meant to assure the former "untouchables", a place in the educational system, and in the public professions, not only to counter economic deprivation. The scheduled tribes were granted reservations on another ground that of being far removed from the mainstream of Indian society. In the process, India took a step beyond egalitarianism; it progresses from basic tenets of formal equality, to egalitarianism, to protective discrimination. But in reality firstly reservation has become the political strategy. Secondly, it has found an unfortunate tendency to confuse protective discrimination with affirmative action. It is the combination of quotas and lower eligibility criterion that marks protective discrimination in India, and finally reservations are meant to introduce respect for diversity and diversity is meant to ensure toleration and respect for the others between communities. In the process, the realm of egalitarianism has narrowed down rather than expanded. Whereas issues of land reforms have been consigned to the dustbin of history, reservations have expanded to rather absurd proportions for a soft option for political agenda (Chandhoke: 2006).

The steady expansion of the institutions without any concern for quality of the faculty is the origin of the decline and fall of the publicly funded higher education system in India. Poor quality then gets embedded within the system. The seats reserved for SC, ST and OBC; there will also be approximately $50 \%$ seats increase for maintaining the status quo in the seats left for open competition. In this, behavioral management, discontent is betrayed as an imperfect approach to affirmative action which can credibly motivate the public interest and aspired by all members of society; not to the rights of individuals or groups such as caste. But, the system is eliminating the benefit of affirmative action itself. Iceland of excellence exists; but they may not remain so buoyant if greater numbers are thrown at them immediately. It is entirely conceivable that average levels of learning and research in India have improved in the last 50 years. But, we must entertain the nagging doubt that despite the extraordinary expansion in higher education, the quality of the research output is far from satisfactory. Whatever the government would have given us with one hand, via affirmative action; it would have taken away with the other, via vote-bank politics (Balakrishnan: 2006).

The reservation was a countervailing mechanism against the social discriminative instinct of Indian society. It was like a bitter pill for a sick Indian society, a necessary evil, required as long as the disease lasted. There was an in-built motivation for the society to recover from the disease at the earliest and stop the pills. Since, the disease is basically referred to the caste system; reservations were the catalyst that would hasten its death. Political parties play a major role in inciting reservation agitation was the back-drop to the gujjar unrest in Rajasthan. Reservation has been a surrogate for caste politics and is being skillfully manipulated by the political parties. Reservations-centered politics is played along three main dimensions: one, demanding reservations for certain social groups, e g, dalit Christians, backward Muslims, etc; two, backing demands by certain castes to get included in the reserved categories; and three, inciting demands for a split in the quota by certain sub castes in a conglomerate reserved category (such as madigas in Andhra Pradesh). All of these inevitably create inter-caste conflict, which are manipulated by the parties to their advantage. The author has suggested that the system should be worked as a mechanism to end the caste system. It is a fundamental duty of the state to support the poor and needy, irrespective of caste and creed, in realization of their full human potential (Teltumbde: 2007).

The government had already explicitly rejected the caste as the basis of class and suggested the adoption of "some criteria other than caste", linking backwardness to "occupational communities" and "the application of economic tests" the mess which has been created by the identifying caste with class would have been avoided; and perhaps their report accepted by the government nearly a decade earlier. The author suggested that the Reservations need to be restricted to the really needy who have been oppressed and exploited for long and cannot reasonably be expected to come up on the social and economic ladder without such special dispensation. Those who are economically well-off, or one of whose generation has already availed the benefit of reservation, should be excluded. The concept of creamy layer and the restriction of reservation to only one generation need to be uniformly applied to all reserved categories. Reservations in promotions need to be consistent with the "maintenance of efficiency in administration" as enjoined by Article 335 of the Constitution; and should be no case result in a senior and former boss serving under a junior promoted under the promotion quota. Now it needs to formulate a conscious and comprehensive policy in this regard, vigorously implement and adequately monitor to ensure that all these reserved categories advance economically, socially and educationally at par with the general category of citizens within a specified timeframe and do not need the crutches of reservation (Saksena :2007).

The main aim of the founder of the constitution was to create egalitarian society wherein social, economic and political justice prevailed and equality of status and opportunity are made available to all. The reservation scheme exists to provide opportunities for the members of the SCs and STs to increase their representation in the 
Employment Status of Teaching Positions of Scheduled Castes (SCs) and Scheduled Tribes (STs) ....

state legislatures; the executive appendage of the union and state, the labour force, schools, colleges, and other public institutions. The share of SCs and STs in employment and educational institutions still falls short of the target in certain categories of jobs and higher education. The target in the case of group C and D are close to population mark of $15 \%$ for SCs and 7.5\% for STs; but fall short in groups A and B. With the growth of share of SCs and STs in Public services; it has positive multiple effects on the social and economic situation of these two disadvantaged groups. The author argued that the reservation did not provide equal opportunity within each group/community to all beneficiaries. The policy was initially planned only for 10 years after the independence; but till now it is continued and no one has taken any step to amend it or revise it or to change it. The reason behind is nearly $33 \%$ voting done by SCs and STs; so now if they make any change in the reservation policy against them, then they have to suffer a lot for the same. So they are not taking any step against the reservation (Jangir: 2013).

The above studies highlighted some of the components of backwardness, discrimination and deprivation; reservation policies and of SCs/STs; affirmative action plans; employment positions in central Universities; disparities between SC/STs and non SC/STs and the human development of SCs/STs; expansion of quality of the faculty in higher education and the egalitarian society etc. The present study/paper focuses on the following objectives:

Objectives: The following are the objectives the study:

1. To study the sanctioned teaching positions of Professor, Associate Professor and Assistant Professor in the selected central universities i.e. Banaras Hindu University (BHU), Delhi University (DU), Jawaharlal Nehru University (JNU) and University of Hyderabad (UoH) in India.

2. To study the status of filled-up teaching positions of Professor, Associate Professor and Assistant Professor in the selected central universities i.e. Banaras Hindu University (BHU), Delhi University (DU), Jawaharlal Nehru University (JNU) and University of Hyderabad (UoH) in India.

3. To identify the Short-fall in the teaching positions of Professor, Associate Professor and Assistant Professor in the selected central universities i.e. Banaras Hindu University (BHU), Delhi University (DU), Jawaharlal Nehru University (JNU) and University of Hyderabad (UoH) in India.

4. To study the employment status of SC/ST teaching positions of Assistant Professors, Associate Professors and Professors level in Banaras Hindu University (BHU), Delhi University (DU), Jawaharlal Nehru University (JNU) and University of Hyderabad (UoH) in India.

\section{Methodology}

The present study is based on secondary data which is collected from Annual reports of University Grants Commission (UGC), New Delhi, annual reports of Ministry of Human Resource Development (MHRD), annual reports of Banaras Hindu University (BHU), Delhi University (DU), Jawaharlal Nehru University (JNU) and University of Hyderabad (UoH) in India. Current Roster records of Banaras Hindu University (BHU) and Delhi University (DU) acquired through the Right to Information Act (RTI). Some of the data are compiled from the Post Based Revised Recruitment Rosters of Universities retrieved from the concerned University websites. The relevant data was also collected from the Journals and other Committee's reports. The results are presented in the form of simple tables and text.

Brief Profiles of the Universities under Study: In case of the four central universities in India under the study, first comes Banaras Hindu University (BHU); second is Delhi University (DU); third Jawaharlal Nehru University (JNU) and fourth is University of Hyderabad (UoH). Banaras Hindu University is a Public Central University located in Varanasi, Uttar Pradesh, which established in 1916 with the initiative of Pandit Madan Mohan Malviya. BHU is one of the largest residential Universities in Asia, with over 20,000 students. The university's main campus spread over 1,300 acres $\left(5.3 \mathrm{~km}^{2}\right)$ and the Rajiv Gandhi South Campus located in Barkachha in Mirzapur district is spread over 2,700 acres $\left(11 \mathrm{~km}^{2}\right)$. BHU has 4 institutes and 14 faculties (streams) and more than 140 departments. The President of India shall be the Visitor of the University. The Chancellor shall be elected by the Court, advisory body, authority of the University and the Vice-Chancellor shall be appointed by the Visitor on the recommendation of a Selection Committee constituted by the Visitor for the purpose. Chancellor and Vice-Chancellor shall hold office for a term of three years. The University has 4 affiliated colleges that have liberal courses in humanities, social sciences and science courses. There is maximum 1862 teaching staff sanctioned in the Banaras Hindu University followed by Delhi University with 1106 teaching staff.

The University of Delhi is a Public Central University located in Delhi, India. It is wholly funded by the government of India. It was established in 1922 as a unitary, teaching and residential university by an Act of the 
Employment Status of Teaching Positions of Scheduled Castes (SCs) and Scheduled Tribes (STs) ....

Central Legislative Assembly. The President of India is the Visitor, the Vice Precedent is the Chancellor and the Chief Justice of the Supreme Court of India is the Pro-Chancellor of the university. The University has 65 colleges that have liberal courses in humanities, social sciences and science courses. Twenty five of these colleges are affiliated with the South Campus while the others are to the North Campus. These colleges except two, Lady Irvin college and Institute of Home Economics, are undergraduate colleges. The number of colleges under the university goes up to 77, if the colleges that run professional courses are included. Delhi University declared as "Best University in India' by Brands Academy at its 'Education Excellence Awards' 2014.

Jawaharlal Nehru University is a Central University in New Delhi, formally inaugurated on 14 November 1969. The campus is spread over approximately 1, 000 acres of land on the Aravali range in New Delhi. Presently the University has over 7, 300 students and 2, 075 teaching and non-teaching employees, who come from all parts of the country and abroad, and from all sections of society. University is broadly structured into Schools, each with constituent Centres. Today, the University has ten Schools and four special centers. Several Centers in Schools of the University have been declared by the UGC to be Centers of 'Excellence'. The NAAC Peer Team visited the University during $18-20$ June, 2012 for performance evaluation and the NAAC has accredited the JNU with the award of Grade -A and CGPA of 3.91/4.00, the highest in the country which accredited is for five years.

The University of Hyderabad, a premier institution of post graduate teaching and research in the country, was established by an Act of Parliament (Act No. 39 of 1974) on $2^{\text {nd }}$ October, 1974 as a Central University. The University has 46 departments and centers organized in 12 schools and the university has over 400 faculties and about 5000 students. The number of teaching staffs is 399 and number of female teachers is 100 and number of nonteaching staff is 1075 . The teacher student's ratio is $1: 12$ and teaching to non-teaching ratio is $1: 2.69$. NAAC has accredited the UoH with the award of Grade A and CGPA of 3.72/4.00 the accredited is for five years. In 2012 the university was ranked seventh, ahead of the Indian Institute of Science, as published by India Today.

There are total 657 posts are vacant in BHU; 953 posts are vacant in DU; 299 posts are vacant in JNU and 144 posts are vacant in UoH under Assistant Professors, Associate Professors, and Professors category. In BHU out of 657 vacant posts, 253 posts are vacant under General category; 178 posts are vacant under SC category; 111 posts are vacant under ST category and 115 posts are vacant under OBC category. In DU, out of 953 vacant posts, 622 posts are vacant under General category; 146 posts are vacant under SC category; 70 posts are vacant under ST category; 115 posts are vacant under OBC category and 31 posts are vacant under PWD category. In JNU, out of 299 vacant posts, 164 posts are vacant under General category; 73 posts are vacant under SC category; 38 posts are vacant under ST category; 24 posts are vacant under OBC category and 22 posts are vacant under PWD category. In University of Hyderabad, out of 144 vacant posts, 91 posts are vacant under General category; 29 posts are vacant under SC category; 6 posts are vacant under ST category; 22 posts are vacant under OBC category and 3 posts are vacant under PWD category.

\section{Main Findings}

There are total 15,573 teaching posts are sanctioned in all Central Universities in India, in which 11,202 posts are sanctioned in Non-NER Central Universities; total 15,573 posts are sanctioned in NER Central Universities; and 1,918 posts are sanctioned in new Central Universities of India. Out of total 15,573 posts, 2,249 posts are sanctioned for Professors category; 4, 464 posts for Associate Professors category and 8,860 posts are sanctioned for Assistant Professors category. In our study we have taken 4 major central universities i.e. one Banaras Hindu University from Varanasi; Delhi University from Delhi; Jawaharlal Nehru University, New Delhi and University of Hyderabad, A.P. There are maximum 1,862 posts sanctioned in Banaras Hindu University for teaching staff, followed by Delhi University with 1,706 posts; Jawaharlal Nehru University with 809 posts and University of Hyderabad with 556 posts (UGC Data accessed from www.ugc.ac.in).

Banaras Hindu University: Table -1 represents that in Banaras Hindu University, in which total 1, 862 posts are sanctioned for teaching employees and 7, 223 posts are sanctioned for non-teaching employees. In teaching employees, out of total 1, 862 posts, 246 posts are sanctioned for Professors category; 511 posts sanctioned for Associate Professors category and 1, 105 posts are sanctioned for Assistant Professors category. In the Professors category, out of 246 posts, 192 posts are reserved for General category; 36 posts are reserved for Schedule Castes and 18 posts reserved for Schedule Tribes. Out of total 246 posts, only 126 posts were filled-up by general category employees and no post was filled-up by SC, ST, and OBC category of Professors. So, there are total 66 posts are vacant under general category; 36 posts are vacant under SC category and 18 posts are vacant under ST category. BHU has advertised total 120 posts of Professors category in which 64 posts are reserved for general category; 35 posts are reserved for SC category; 16 posts for ST category and 5 posts are reserved under PH (PWD) category. 
Employment Status of Teaching Positions of Scheduled Castes (SCs) and Scheduled Tribes (STs) ....

In case of Associate Professors category, out of 511 sanctioned posts, 76 posts are reserved for SC category and 38 posts are reserved for ST category. Out of total 511 posts, 304 posts were filled by general category people and only 3 posts were filled-up by SC category people and no post under ST category was filled-up. So there are 93 posts are vacant under General category; 73 posts are vacant under SC category and 38 posts are vacant under ST category employees. BHU has advertised 87 posts under general category; 70 posts for SC category; 36 posts for ST category; and 11 posts are under PH (PWD) category at Associate Professors level. At Assistant Professor level, out of total 1,105 posts, 560 posts are reserved under General category; 165 posts are reserved for SC category; 82 posts are reserved for ST category and 298 posts are reserved under OBC category. Within 298 posts of OBCs, 164 positions of Assistant Professors are currently occupied by Un-Reserved (UR). As and when these positions shall fall vacant, the same shall be filled by OBC candidates. In case of general category, 620 posts are filled-up and 104 posts are already vacant because 164 posts of Assistant Professors under OBC category is currently occupied by General Category.

Table -1: Teaching Positions in Banaras Hindu University, Varanasi, U .P.

\begin{tabular}{|c|c|c|c|c|c|c|c|c|c|c|c|c|c|c|c|c|c|c|}
\hline \multirow[t]{2}{*}{$\begin{array}{l}\text { Name of } \\
\text { the post }\end{array}$} & \multirow{2}{*}{$\begin{array}{c}\text { Sanc } \\
\text { tione } \\
d \\
\text { post }\end{array}$} & \multicolumn{4}{|c|}{ Identified post } & \multicolumn{4}{|c|}{ Filled up } & \multicolumn{4}{|c|}{ Vacant post } & \multicolumn{5}{|c|}{$\begin{array}{c}\text { Advertised post against the } \\
\text { vacant positions } * *\end{array}$} \\
\hline & & Gen & SC & ST & OBC & Gen & SC & ST & $\mathbf{O B C}$ & Gen & SC & ST & OBC & Gen & SC & ST & OBC & PH \\
\hline $\begin{array}{l}\text { Associate } \\
\text { Professor }\end{array}$ & 511 & 397 & 76 & 38 & - & 304 & 03 & - & - & 93 & 73 & 38 & - & 87 & 70 & 36 & - & 11 \\
\hline $\begin{array}{l}\text { Assistant } \\
\text { Professor }\end{array}$ & 1105 & 560 & 165 & 82 & $\begin{array}{c}* 29 \\
8 \\
\end{array}$ & 620 & 91 & 26 & 17 & 104 & 74 & 56 & 117 & 98 & 71 & 55 & 111 & 16 \\
\hline Total & 1862 & 1149 & 277 & 138 & 298 & 1050 & 94 & 26 & 17 & 263 & 183 & 112 & 117 & 249 & 176 & 107 & 111 & 32 \\
\hline
\end{tabular}

Note: No reservation for OBC category exists in the University for the Post of Associate Professor and Professor.

* 164 positions of Assistant Professor under OBC category is currently "occupied by Un-Reserved (UR)". As and when these positions shall fall vacant, the same shall be filled by $O B C$ candidates.

** Advertised posts vide Advt. No. 04/2012-13, Rolling Advt. No. 05/2012-13 \& 02/2013-2014.

In case of SC category, out of 165 posts, 91 posts were filled-up and 71 posts are vacant. In case of ST Category, out of 82 posts, 26 posts were filled-up and 55 posts are vacant and In case of OBC Category, out of 298 posts, 17 posts were filled-up and 117 posts are vacant. BHU has advertised the total 249 posts in the general category; 176 posts reserved for SC category and; 107 posts are reserved for ST category and 111 posts are reserved for OBC category for Assistant Professors.

Out of total 1862 teaching posts, 277 posts are reserved for SC, 138 posts are reserved for ST category and 298 posts are reserved for OBC category. In case of SC category, out of 277 teaching posts, only 94 posts are filledup and 183 posts are vacant. In case of ST category, out of total 138 posts, only 26 posts are filled-up and 112 posts are vacant and in case of OBC category, out of total 298, only17 posts are filled-up by OBC candidates and 164 posts filled-up by Un-Reserved (UR) candidates and 117 posts are vacant. BHU has Advertise the total of 176 posts reserved for SC and 107 posts are reserved for ST and 111 posts reserved for OBC category.

University of Delhi: The Post Based Reservation positions of teaching faculty members of Assistant Professor, Associate Professor and Professor levels are shown as under:

Table- 2: Post Based Reservation position of teaching faculty in the University of Delhi, Delhi, (As on September, 2013)

\begin{tabular}{|c|c|c|c|c|c|c|c|c|c|c|c|}
\hline \multirow[t]{2}{*}{ Department } & \multirow{2}{*}{$\begin{array}{c}\text { Post } \\
\text { Sanctioned }\end{array}$} & \multirow[t]{2}{*}{ Existing } & \multirow{2}{*}{$\begin{array}{c}\text { Total } \\
\text { Vacancy }\end{array}$} & & \multicolumn{4}{|c|}{ Vacant } & \multicolumn{3}{|c|}{ Short-fall } \\
\hline & & & & SC & ST & OBC & UR & PWD & SC & ST & OBC \\
\hline Assistant Professor & 794 & 374 & 420 & 63 & 33 & 115 & 200 & 09 & 17 & 17 & 83 \\
\hline Associate Professor & 648 & 265 & 383 & 60 & 29 & - & 278 & 16 & 37 & 19 & - \\
\hline Professors & 264 & 114 & 150 & 23 & 08 & - & 113 & 06 & 16 & 11 & - \\
\hline Total & 1706 & 753 & 953 & 146 & 70 & 115 & 591 & 31 & 70 & 47 & 83 \\
\hline
\end{tabular}

Source: Compiled from the Post Based Revised Recruitment Roster, w. e. f. September, 2013, University of Delhi,

Delhi, accessed through www.du.ac.in.

Table-2 shows that there are total 1,706 posts are sanctioned for teaching employees in Delhi Universities. Out of 1,706 posts, 264 posts are sanctioned for Professors category; 648 posts are sanctioned for Associate Professors and 794 posts are sanctioned for Assistant Professors category. In Assistant Professors category only 374 
Employment Status of Teaching Positions of Scheduled Castes (SCs) and Scheduled Tribes (STs) ....

Posts are filled-up and 420 posts are vacant in the University. Out of total 420 vacant posts, 63 posts are vacant under SC category; 33 posts are vacant under ST category; 115 posts are vacant under OBC category; 200 posts are vacant under UR category and 9 vacant posts are vacant under PWD category. There are total 17 posts are shortfall under SC category; 17 posts are shortfall under ST category and 83 posts are shortfall under OBC category in Delhi University.

In Associate Professor's category, out of 648 sanctioned posts only 265 Posts are filled-up and 383 posts are vacant in the University. Out of total 150 vacant posts, 60 posts are vacant under SC category; 29 posts are vacant under ST category; 278 posts are vacant under UR category and 16 vacant posts belong to PWD category. There is total 37 posts are shortfall under SC category and 19 posts are shortfall under ST category in Delhi University.

In Professor's category only 114 Posts are filled-up and 150 posts are vacant in the University. Out of total 150 vacant posts, 23 posts are vacant under SC category; 8 posts are vacant under ST category; 113 posts are vacant under UR category and 6 vacant posts belong to PWD category. There are total 16 posts are shortfall under SC category and 11 posts are shortfall under ST category in Delhi University.

Jawaharlal Nehru University: The University has already adopted reservation policy for SCs and STs to the extent of $15 \%$ and $7.5 \%$ respectively at the level of Assistant Professor. The University has also adopted the reservation for SCs and STs in the teaching posts at the level of Professor and Associate Professor [vide E.C. Resolution dated 11.04.2007]. The reservation for OBCs has been adopted in teaching posts at the level of Assistant Professor [vide E.C. Resolution dated 11.4.2007]. The reservation at the level of Assistant Professor was implemented vide E.C. Resolution dated 29.11.1999. Further the University has also adopted reservation for Persons with Disability (PWD) in teaching posts at the level of Associate Professor and Professor, vide, E.C. Resolution dated 11.4.2007.

Table -3 represents that in JNU, there are only 85 (47.3\%) posts were filled-up and $95(52.77 \%)$ posts are vacant out of total 180 sanctioned positions under Professor's category. At the Associate Professors level 183 (58\%) posts were filled-up and $133(42.08 \%)$ posts are vacant and at the Assistant Professor's level out of 313 sanctioned posts, only 211(67.4\%) posts are filled-up and $102(32.6 \%)$ positions are vacant. There are no reserved filled-up positions in SC and ST categories at the Professor and Associate Professor Levels; but at the Assistant Professor level, 27 posts from SC and 10 posts from ST categories were filled-up.

Table -3: Status of Representation of SC/ST/OBC/PWD in teaching posts in JNU (as on 31.03.2013)

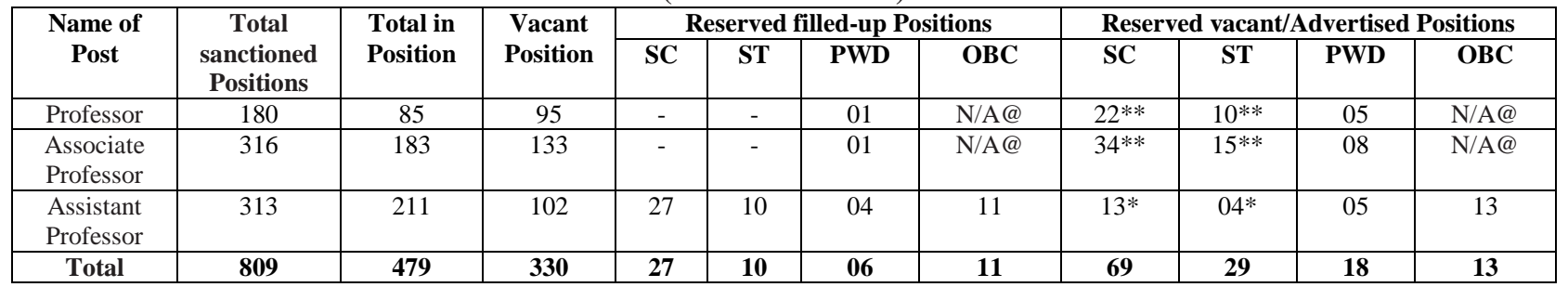

@ OBC reservation does not apply to these posts.

* These Posts already advertised and are in process of holding interviews.

** Advertisement will be sent to press very shortly.

Source: $43^{\text {rd }}$ Annual Report 2012-13, JNU.

There are 19 reserved posts advertised and it is in the process of holding interviews at Assistant Professors level. The Advertisement will be sent to press very shortly for the total of 81 reserved positions for SC and ST categories in which 32 posts are of professor level and 49 posts are of Associate Professors level.

University of Hyderabad: There are total 556 posts sanctioned under XI plan and earlier plans including those sanctioned under UGC and other bodies in which only $412(74.1 \%)$ posts have been filled-up and 144 (25.9\%) posts are vacant. Out of 144 vacant posts, the highest 60 (41.6\%) positions are in the Associate Professors category; 54 (37.5\%) positions are in Assistant Professors Category and 30 (20.83\%) positions are in the Professors category. In filled -up positions category, out of 412 posts, the highest 169 (41.01\%) positions are filled-up with the Associate Professors; 165 (40.04\%) positions are filled-up with the Assistant Professors and 78 (18.93\%) posts are filled-up by the Professors category. 
Employment Status of Teaching Positions of Scheduled Castes (SCs) and Scheduled Tribes (STs) ....

Table 4: Particulars of teaching posts in University of Hyderabad under XI plan and earlier plans including those sanctioned under UGC and other bodies, No. of posts filled and the vacant posts as on 01/01/2014.

\begin{tabular}{|c|c|c|c|c|c|c|c|c|c|}
\hline \multirow[t]{2}{*}{ Designation } & \multirow{2}{*}{$\begin{array}{l}\text { No. of posts } \\
\text { sanctioned }\end{array}$} & \multirow{2}{*}{$\begin{array}{l}\text { No. of Posts } \\
\text { filled up to } \\
31 / 03 / 2013\end{array}$} & \multirow{2}{*}{$\begin{array}{c}\text { No. of Posts filled up to } \\
\text { 01/01/2014 }\end{array}$} & \multicolumn{6}{|c|}{ No. of vacant posts as on $01 / 01 / 2014$} \\
\hline & & & & General & SC & ST & OBC & PWD & Total \\
\hline Professor & 108 & 84 & 78 & 22 & 05 & 03 & 00 & 01 & 30 \\
\hline $\begin{array}{l}\text { Associate } \\
\text { Professor }\end{array}$ & 229 & 160 & 169 & 36 & 15 & 09 & 00 & 03 & 60 \\
\hline $\begin{array}{l}\text { Assistant } \\
\text { Professor }\end{array}$ & 219 & 156 & 165 & 33 & 05 & 03 & 13 & 02 & 54 \\
\hline Total & 556 & 400 & 412 & 91 & 25 & 15 & 13 & 06 & 144 \\
\hline
\end{tabular}

Source: $38^{\text {th }}$ Annual Report (2012-2013), University of Hyderabad, A.P. and UGC data accessed from www.ugc.ac.in

There are 15 posts in Associate Professor Level and 5 posts are in the Assistant Professor and Professor level are vacant under SC category. Under ST category 9 posts are vacant in Associate Professor Level and 3 posts are vacant in Assistant Professor and Professors level. Under OBC category 13 posts are vacant in Assistant Professor Level. The university data shows that the actual strength of the teaching faculty, the Professors category was 170, which is comprised of filled -up posts as per the posts sanctioned was 84 and promoted as professors under Merit Promotion/CAS was 86 in number. Similarly actual strength of Readers reveals that the filled-up posts as per the posts sanctioned was 160 and the posts upgraded to Professors under CAS was 70 (160-70=90) including the 16 were promoted from Lecturer under CAS. Therefore, the actual strength of Readers was 106 only. In case of Lecturer, the actual strength was 117 in number which comprises of the filled-up posts as per the sanctioned posts were 156 and posts upgraded to Readers/Professors were 39 in number $(156-39=117)$.

\section{Conclusion}

In all central universities, out of total 15, 573 sanctioned posts, 4, 933 (31.67\%) posts are sanctioned in four selected central Universities i. e. BHU, DU, JNU and UoH. In all central universities of India, out of 15, 573 posts, 9, $866(63.35 \%)$ posts are filled-up. In case of total 4, 933 sanctioned posts in DU, BHU, JNU and UoH, the total of 2, $880(58.38 \%)$ posts are filled-up. In case of total 9,866 filled-up posts in all central universities, the total $29.19 \%$ of teaching posts are filled by BHU, DU, JNU and UoH. So, in all central universities, 36.65\% posts are vacant in which $41.62 \%$ posts vacant in four selected central universities under study in India. If we examine the individual Universities, $35.28 \%$ of teaching posts are vacant in BHU; 55.86\% posts are vacant in DU; 36.95\% posts are vacant in JNU and $25.89 \%$ posts are vacant in $\mathrm{UoH}$. The new scheme has been introduced to provide central financial assistance for establishment of a Model Degree College in each of the identified 374 Educationally Backward Districts (EBDs) where Gross Enrolment Ratio (GER) for higher education is less than the national (GER). The main objective of the scheme is to enhance the access to degree courses in EBDs of the country, so as to achieve expansion in higher education with inclusion, equity and quality.

\section{Suggestions}

The following suggestions are based on the field observations including the interactions with the respondents from the selected universities (DU, BHU, JNU and $\mathrm{UoH}$ ) under study during the primary data collection during the year 2013-14. For the improvement of quality of higher education, it needs to be filled-up all the vacant posts of teaching in the Universities and colleges. There are enough candidates now available from the SC/ST community, who can take-up the teaching positions and non-teaching positions; but the unwillingness from the university authorities is the main cause for non- filling-up of the vacant posts.

A positive attitude with implementation of affirmative action plan for SC/ST communities can bring the positive change in the society. The discriminative academic environment must be replaced by the creative environment for improvement in the equality of higher education and dignity of all the employees. The strict action should be taken against the universities which are not implementing the reservation policy in recruitment of the backlog vacancies. For these national monitoring committees should be constituted by the regulatory/constitutional bodies for roster preparation and ensuring the strict implementation of reservation policy to ensure the development of these Universities at all levels. 


\section{References}

[1]. $\quad$ Apana, B. (1990), "Reservation and Merit" Economic and Political Weekly, Vol. 25, No. 38, pp. 2110.

[2]. Balakrishnan, Pulapre, (2006), "Higher Education Needs a Longer View", Economic and Political Weekly, Vol. 41, No. 32, pp. 34583459.

[3]. Chandhoke, Neera (2006), "Three Myths about Reservations", Economic and Political Weekly, Vol. 41, No. 23, pp. $2289-2290$.

[4]. Chitnis, Suma (1999), "The Transformation of an Imperial Colony into an Advanced Nation: India in Comparative Perspective" in (ed.), Philip G. and Patti McGill Peterson, "Higher Education in the 21st Century: Global Challenge and National Response", Altbach,

[5]. IIE Research Report, Number Twenty-nine.

[6]. Department of Higher Education, Ministry of Human Resource Development, Government of India, Annual Report: 2012-2013, New Delhi.

[7]. Jangir, Suneel Kumar "Reservation policy and Indian constitution in India", American Internal Journal of Research in Humanities, Arts, and Social Sciences, pp. 126-128.

[8]. Jawaharlal Nehru University $43^{\text {th }}$ Annual Report 2012-2013.

[9]. Kumar, Pradeep (2001), "Reservations within Reservations: Real Dalit-Bahujans”, Economic and Political Weekly, Vol. 36, No. 37, pp. 3505-3507.

[10]. Louis, Prakash (2003), "Scheduled Castes and Tribes: The Reservation Debate", Economic and Political Weekly, Vol. 38, No. 25, pp. 2475-2478.

[11]. Maiti, Prasenjit (2001), "World view: Expansion without funding", The Times Higher Education Supplement, October 5, 2001.

[12]. Ministry of Human Resource development, Department of Higher Education, The report of All India Survey on higher Education, 2010-11, New Delhi.

[13]. Ministry of Human Resource development, Department of Higher Education The report of All India Survey on higher Education, 2011-12 (Provisional).

[14]. Saksena, K. D., (2007), "Policy Changes Needed on Reservations", Economic and Political Weekly, Vol. 42, No. 26, pp. 2494-2495 and 2497-2498.

[15]. Shah, A.M. (1991), “Job Reservations and Efficiency”, Economic and Political Weekly, Vol. 26, No. 29, pp. 1732-1734.

[16]. Teltumbde, Anand (2007), "Reverting to the Original Vision of Reservations" Economic and Political Weekly, Vol. 42, No. 25, pp. 2383-2385.

[17]. Thorat, Sukhadeo and Senapati, Chittaranjan "Reservation in Employment, Education and Legislature — Status and Emerging Issues", Working Paper Series: Indian Institute of Dalit Studies, New Delhi.

[18]. Thorat, Sukhadeo (2005), "Reservation and Efficiency Myth and Reality" Economic and Political Weekly, pp. 808-810.

[19]. Tilak, Jandhyala B.G. (1997), "The dilemma of reforms in financing higher education in India", Higher Education Policy, Volume 10, No. 1 .

[20]. UGC, Annual Report, 2011-2012.

[21]. University of Hyderabad, $38^{\text {th }}$ Annual Report 2012-2013.

[22]. Virginius Xaxa (2002), "Ethnography of Reservation in Delhi University" Economic and Political Weekly, Vol. 37, pp. 2849-2851 and 2853-2854. 